\title{
Community Knowledge and Attitude on Recognizing the Nutrients in Clay Utensils. A Cross Sectional Study.
}

\author{
Parijatha Bandigari $^{1 *}$, Mayuri Konda ${ }^{2}$, Swapna Neela ${ }^{2}$, Saritha Manne', \\ Hareesh Annaram ${ }^{3}$, Sai Rupesh Kavuturi ${ }^{3}$ \\ ${ }^{1,2,3}$ Department of Pharmaceutical Sciences, School of Pharmacy, Nalla Narasimha Reddy \\ Educational Society's Group of Institutions, Hyderabad, India - 500088. \\ *Corresponding Author E-mail: parijatha.pharmacy@gmail.com
}

\begin{abstract}
Now a day's people are more aware about the dangers of modern cookware made up of different metals and turned towards the traditional cookware made up of stone and clay materials. Clay utensils makes food beautiful apart from that these vessels have an Ayurvedhic and therapeutic advantage. In this project it explains about the effective usage of Clay utensils in daily life, an online survey has been successfully carried out to investigate a variety of research questions, including in clinical, academic, and administrative settings. This survey revealed that Clay pots and Clay Utensils are having more advantageous and beneficial effects on Health. Now a days are Web-based surveys are using commonly in medical research. These surveys provide rapid and accurate results with low cost and minimum errors.
\end{abstract}

Key words: Clay Utensils, beneficial effects.

\section{INTRODUCTION}

For the collection of both quantitative and qualitative data Surveys are well-established tools to use. Given the widespread popularity of Web-based surveys, it is valuable for investigators to be familiar with this modality (Abdulaziz A et.al 1999). Survey-based research analyze characteristics of a defined population by using a questionnaire and collects participants' responses. 


\subsection{Clay Pots and Utensils}

From centuries ago, we are using clay or earthen pots (glazed and unglazed) and iron utensils for cooking. Now we have shifted to modern cookware such as non-stick pans, non- stick kadhai, pressure cookers etc. Also we are using various grinders, mixers, microwave oven for size reduction and easy cooking viz. Our parent remembers the taste of food cooked in earthen pot. It is now important to understand the key facts of using earthen pots for cooking. All the foods and drinks lie between a range of acidic and alkaline nature (Krämer P et.al 2009). Clay is in alkaline nature. Clays are plastic, means that it can be molded into any shape. Clay is the primary layer of earth and it is available almost everywhere. Clay is in abundant on earth and can be found in the soil.

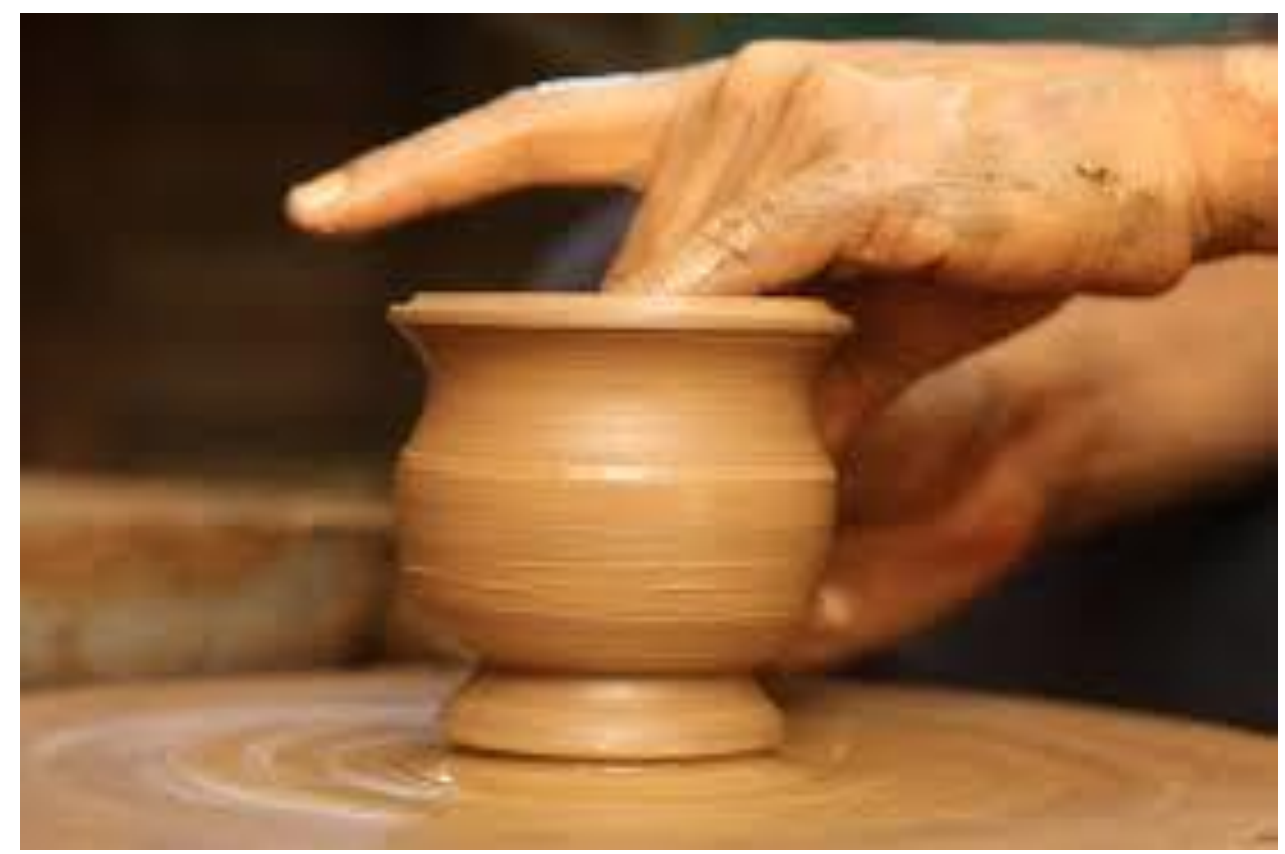

Figure: 1 Making of Clay pots

\subsection{Health Benefits and advantages of Clay Pot Cooking}

- Clay utensils provides plenty of moisture and circulate steam throughout cooking means that it uses less oil and fat to cook.

- Since Clay is alkaline in nature and contains many nutrients and vitamins because of its alkaline nature it acts like natural detox.

- The food is much tastier due its slow cooking process and retains its nutrients.

- Clay pot retains the temperature for a longer time and reheating is not required

- If the pot is season properly, it will become durable and likely last for a long time. Without proper seasoning, however, there's a high risk of the pot cracking.

Clay pots are less expensive than the metal, cast iron cookware. On the other hand, you cannot deny that clay pots are quality cookware with too many health benefits and easy to handle (Ebrahimi R et.al 2015). Cooking in clay pots increases the overall taste of the food, and that's why more people are considering cooking in clay pots. Apart from the minor disadvantages clay pots are having many advantages to use in daily life. 


\subsection{Cleaning the Clay Pot}

Because clay is porous, soap or normal dishwashing detergent cannot be used. The soap will soak into the clay and end up leaching into the next meal that cook in the pot. Baking soda, hot water and a stiff brush helpful for cleaning clay pots (Semwal D, et.al 2006).

\subsection{Disadvantages of Cooking in Clay Pots}

Clay pots are delicate and they are porous in nature so that cleaning of clay pot is little bit difficult (Raipally A et.al 2015). Clay pots can get hot quickly: It is important to carefully cook food in clay pots because they get hot quickly and burn the hands. However, it also gets cools down quickly. So, make sure you keep your children away from the kitchen while cooking food in clay pots.

\section{METHODS}

There are many survey methods are used for data collection, the most common being questionnaires, which can be delivered on paper, either in person or by mail (Assi MA et.al 2016). With over $300 \mathrm{Web}$-based survey software programs available, there are many options and factors to consider when deciding which is the most appropriate tool for one's research investigation (Assi MA et.al 2016).

\subsection{Quantitative research}

A research design has the main goal of generating answers to research problems. A quantitative research design was chosen for this study. Quantitative research has been defined in very broad types of research that entails the collection of numerical data, a deductive relationship between theory and research and an objective conception of social reality. Quantitative research, therefore, involves a range of methods concerned with the systematic investigational of social phenomena, using statistical or numerical data The decision to choose a quantitative research design was primarily guided by the philosophical assumptions and research questions of the study, as well as an examination of the available literature on the topic area. Looking at the nature of the research questions of thisstudy, choosing a quantitative design provided the tools to answer these questions. Here the quantitative research design that would provide baseline information on this topic area was required.

For this study, a cross-sectional survey design was employed. Cross-sectional survey design involves the distribution of questionnaires, or may be conducted by interview orobservation (Krämer P et.al 2009). This design allows for standardization in the asking of questions and categorization of the answers provided.

The series of questions which were intended to study the attitude of participants regarding Clay utensils usage and its benefits were analyzed, the questionnaire consisted of question to obtain socio-demographic data and close ended questions.

\subsection{Study design}

We used the services of Google and created a Google form to gather data in the month of May, 2021 as it was pandemic period. The link to the questionnaire was sent to individual mails 
and procured the responses. A reminder was sent to those who did not yet complete the questionnaire

\subsection{Survey Instrument}

We developed a questionnaire to assess the perceptions and knowledge of People about clay utensils use. We adapted a questionnaire based survey which was aimed at the knowledge of clay utensils use.

Table 1: Design of questions for the survey

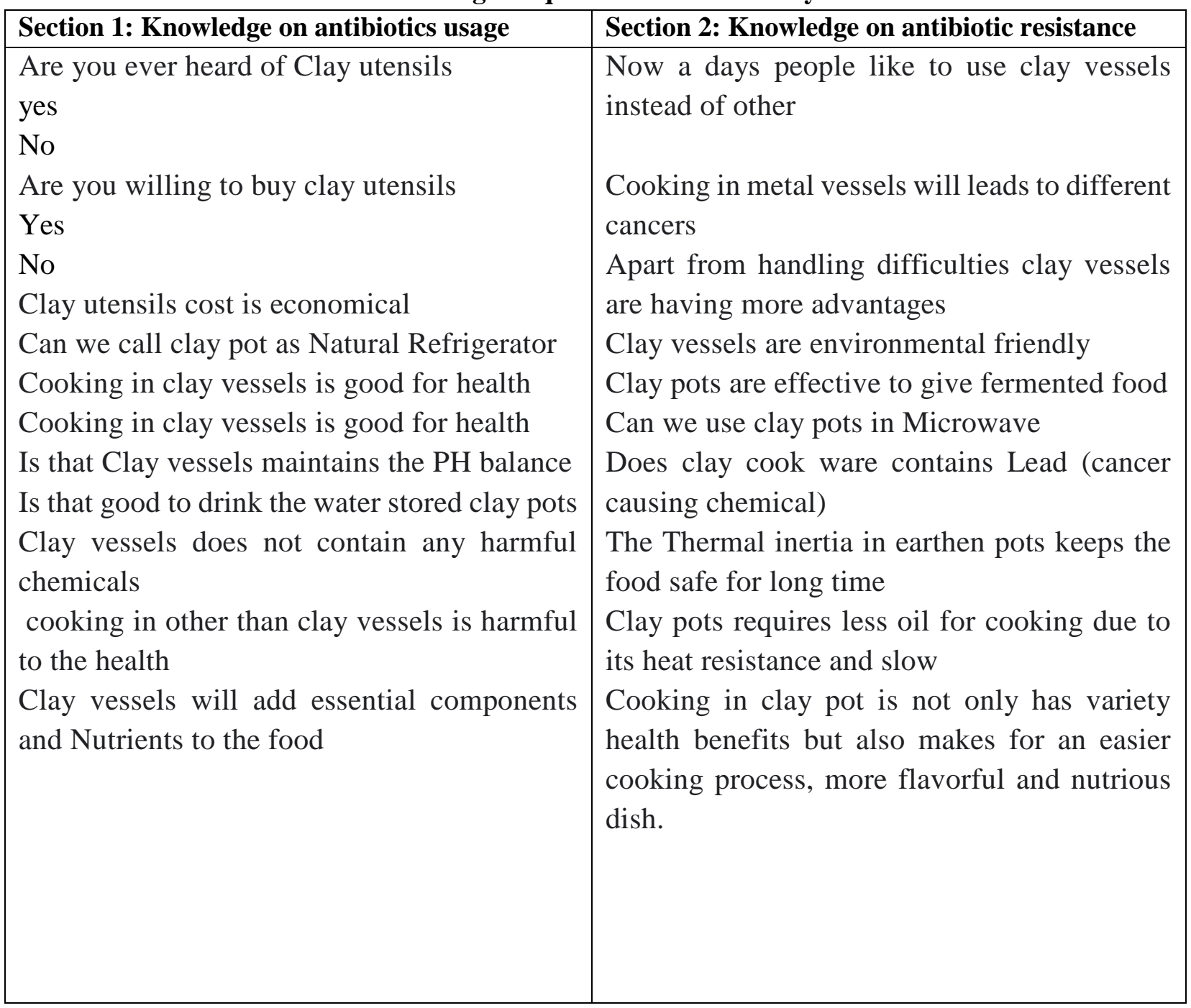

\section{RESULTS AND DISCUSSION}

\subsection{Study design}

Google forms were sent to individual mails and acquired 355 responses. The responses were analyzed and reported. 


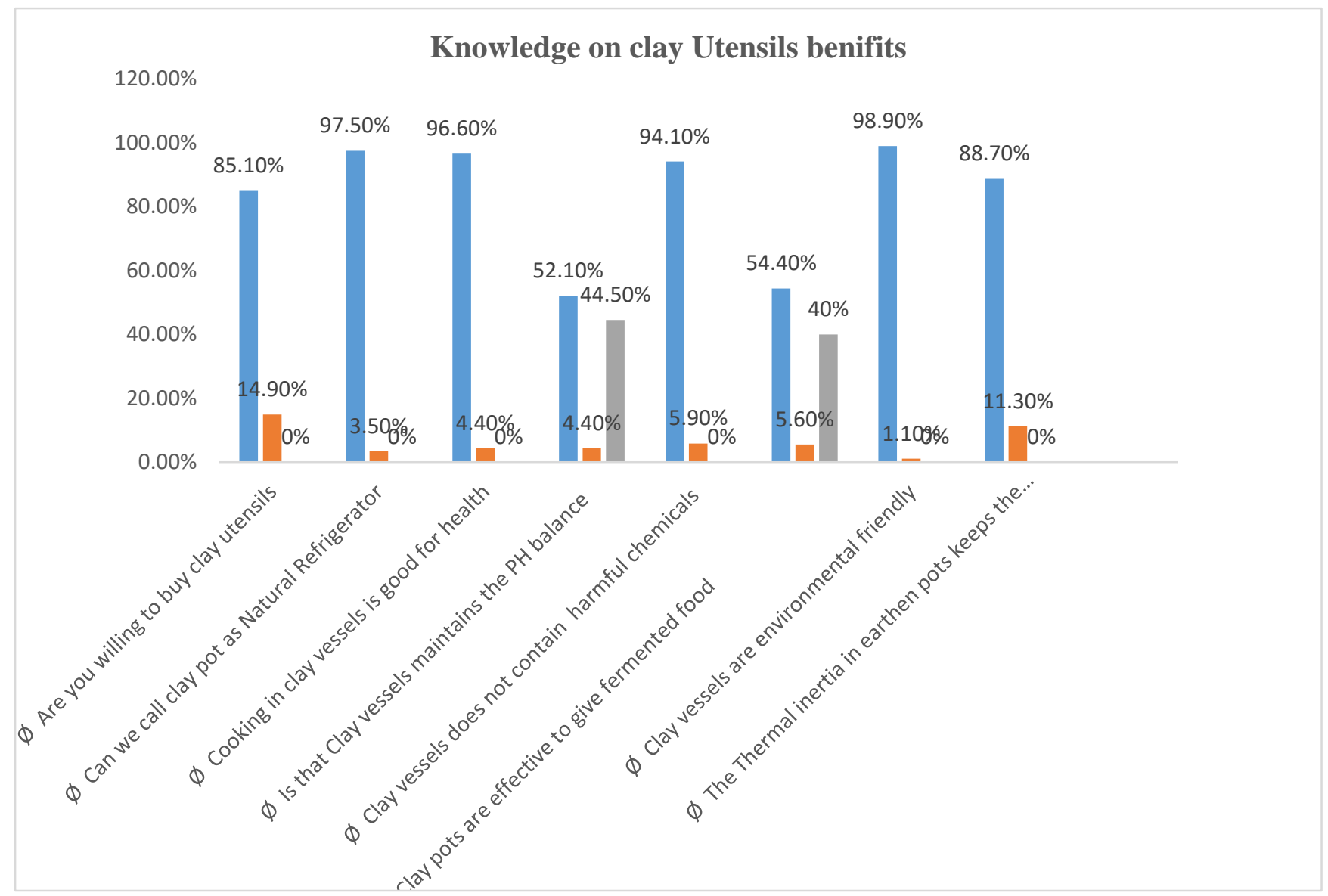

Figure: 2 Knowledge on clay Utensils Benefits

\subsection{Knowledge on clay utensils usage}

One of the rationales behind this survey was to analyze the awareness levels on how to and when to use the

clay utensils. The questions were framed in a manner that information was gathered regarding their awareness on clay utensils From the survey $92.4 \%$ of the participants declared that they are awarw about clay utensils but $7.6 \%$ participants don't know about clay utensils.

Next category of questions include information about whether the participants know about the health benefits of clay utensils by giving the questions like Can we call clay pot as Natural Refrigerator, Cooking in clay vessels is good for health, Is that Clay vessels maintains the PH balance, Is that good to drink the water stored clay pots. $97.5 \%$ participants declared that clay pot is obsolutely a Natural Refrigerator. $96.6 \%$ participants aware about Cooking in clay vessels is good for health and good to drink the water stored clay pots $52.1 \%$ participants as an idea about PH maintainance of clay utensils.

The next few questions were framed to analyze knowledge of the participants about cancer causing heavy metal concentration in metal based vessels. $94.1 \%$ participants as knowledge about Clay vessels and their health benefits and cooking in other than clay vessels is harmful to the health and Cooking in metal vessels will leads to different cancers . 


\section{CONCLUSION}

In this project the effective usage of Clay utensils in daily life, an online survey has been successfully used to investigate a variety of research questions, including in clinical, academic, and administrative settings. This survey concludes that Clay pots and Clay Utensils are more advantageous and beneficial effects on Health. Now a day's people are realized about the facts of old tradition and culture and following the old culture.

\section{ACKNOWLEDGMENT}

Authors are also thankful to management of Nalla Narasimha Reddy Group of Institutions, Chowdariguda, Ghatkesar and students for their support in completing this survey based research.

\section{REFERENCES}

1. Abdulaziz A, Adish PD, Steven A, Esrey PD, Theresa W, Gyorkos PD. Effect of consumption of food cooked in ironpots on iron status and growth of young children: a randomised trial, The Lancet. 1999; 353(9154):712-716.

2. Krämer P, Karhagomba I. The Form Of The Cooking Vessel And The Energetic Efficiency Of Cooking, Journal of Engineering Science and Technology. 2009; 4(3):282- 291.

3. Semwal D, Padmashree MA, Khan GK, Sharma AS. Leaching of aluminium from utensils during cooking of food, Journal of the Science of Food and Agriculture. 2006; 86(14):24252430

4. Raipally A, Agarwal A. What Makes Earthen Pot A Sustainable Design Solution For Water Storage In Rural Indian Context? Cumulus Mumbai, 2015.

5. Ebrahimi R, Jahromi MF, Liang JB, Soleimani AF, Shokryazdan P, Idrus Z (2015) Effect of dietary lead on intestinal nutrient transporters $m R N A$ expression in broiler chickens. BioMed Research Int.

6. Assi MA, Hezmee MN, Haron AW, Sabri MY, Rajion MA (2016) the detrimental effects of lead on human and animal health. Veterinary world9(6):660-671. 